\title{
Comparison of transcriptomic and proteomic analyses to construct a model for the promotion of starch synthesis by ABA in Euryale ferox Salisb. seeds
}

\author{
Peng Wu \\ Yangzhou University \\ Xiang Li \\ Nanchang University \\ Xian Liu \\ Changshu Institute of Technology \\ Xu Xu \\ Yangzhou University \\ Yu Zhang \\ Yangzhou University \\ Liangjun Li ( $\square$ ljli@yzu.edu.cn ) \\ Yangzhou University
}

\section{Research article}

Keywords: Starch, E. ferox (Euryale ferox Salisb.), ABA, proteomics, transcriptomics, WGCNA

Posted Date: March 20th, 2020

DOI: https://doi.org/10.21203/rs.3.rs-18154/v1

License: (c) (1) This work is licensed under a Creative Commons Attribution 4.0 International License.

Read Full License 


\section{Abstract}

Background: Euryale ferox Salisb. is an annual aquatic herb and the only species belonging to the genus Euryale in the Nymphaeaceae family. E. ferox seeds are used in medicine and diets. Starch is the main factor affecting $E$. ferox seed quality, but its regulatory mechanism has not been elucidated.

Results: Herein, four time points of seed development, including after flowering T1 (10 days), T2 (20 days), T3 (30 days) and T4 (40 days), were investigated by using RNA-Seq and iTRAQ technology. Using weighted gene co-expression network analyses (WGCNAs), co-expressed genes and hub genes were identified for each module. Of particular importance are the discoveries of specific modules for seed starch during the seed developmental stages. The candidate regulators of seed starch are involved in the hormonal signaling pathways. Three ABA signaling receptor kinases, EfPYR1, EfSnRK2.1 and EfSnRK2.2, were identified as hub genes functioning in starch synthesis during the seed maturation process. The changes in expression pattern, $A B A$ and starch content also indicated that $A B A$ is positively correlated with starch.

Conclusions: Together, these results indicate that $E$. ferox seed accumulation of starch is promoted by $A B A$, providing new insights into the regulatory mechanism of starch synthesis in $E$. ferox seeds.

\section{Background}

Euryale ferox Salisb. (Nymphaeaceae), an ancient species and an annual aquatic herb with large, prickly, floating leaves, is a basal member of the phylum Magnoliophyta that originated in China and Southeast Asia (Fig. 1). The genus Euryale consists of only a single species, E. ferox, which is characterized by both sexual reproduction and cleistogamy [1]. E. ferox can be grown in lakes, bottoms and raceways, signifying a very important and unique type of hydrophytic plant. In China, E. ferox is a popular aquatic vegetable, whose seeds are called gorgon fruit and are considered a tonic [2]. E. ferox is also a class of plant with medicinal value, and a variety of medicinal ingredients have been isolated and identified in its seeds $[3,4]$. In addition, E. ferox has been proven to treat many diseases, such as chronic diarrhea, hypofunction of the spleen, excessive leukorrhea and kidney problems, for several thousand years in traditional chinese medicine $[4,5]$. With the development of technology, we have a deeper understanding of the effects of E. ferox.

Starch is the main component of E. ferox seeds. The photo-contracted compound produced by the source organ is provided to the storage organ (seed) in the form of sucrose and then formed by the catalytic action of a series of enzymes in the grain. The biosynthesis and accumulation of grain starch is directly related to the production and quality of E. ferox. The biosynthesis of starch from sucrose occurs in the developing endosperm, and several important enzymes are involved in the pathway of starch synthesis $[6,7]$, such as sucrose synthase (SUS), UDP-glucose pyrophosphorylase (UGPase), AGPase, and starch synthase. Starch synthase includes two forms: granule-bound amylose synthesis is controlled by starch synthase (GBSS), and amylopectin synthesis is controlled by soluble starch synthase (SSS) and starch 
branching enzyme (SBE) [8-10]. In previous reports, the activities of SUS, AGPase, SSS, and SBE were associated with grain weight [11-14]. During grain filling, some enzymes express different levels of these enzymes between the inferior and superior caryopses [15]. In addition, starch synthesis is affected by hormones and other factors.

Plant hormones play important roles in regulating grain filling, especially abscisic acid (ABA) $[13,16,17]$. In previous reports, ABA-related mutants were used to establish a relationship between $A B A$ signaling and sugar responses in several sugar response screens [18]. ABA biosynthesis and subsequent ABA signaling through ABI4 regulates glucose responses [19].

ADP-glucose pyrophosphate (AGPase) subunits are involved in starch biosynthesis induced by sugars [20]. In angiosperms, AGPase consists of two small and two large subunits, which are used as glycosyl donors by starch synthases [21, 22]. The allosteric regulation of AGPase activity plays an important role in starch biosynthesis in plants [23]. AGPase transcript levels also control starch production [24]. The expression of the genes encoding AGPase subunits is differentially regulated by tissue specificity and physiological signals. Sugar-induced expression has been described for the small (ApS) and large (ApL1, ApL2 and ApL3) subunits [25-28].

A combination of both sucrose and ABA results in much higher expression levels, suggesting a synergistic interaction [29]. Genetic analysis also confirmed that most glycose-responsive mutants are associated with beta or ethylene. It was previously reported that high concentrations of glucose inhibited the growth of Arabidopsis thaliana seedlings, but ethylene clouds lead to the redevelopment of seeds. Through analysis of endogenous ABA in sugar-responsive mutants (gin1, gin5, isi4, and sis4), the ABA content was found to be lower than in wild type plants [30]. Sugar sensitivity can be restored by adding a particular concentration of ABA to these sugar-insensitive mutants. However, these experiments did not directly prove the relationship between sugar and signaling; Chen et al. subsequently found that glucose directly controls expression of ABA biosynthesis genes [31]. After glucose treatment, the transcription levels of $A B A 1, A B A 2, A B A 3, N C E D 3$ and $A A O 3$ were enhanced. These studies suggest that there may be a unique pathway in which glucose directly regulates the expression and accumulation of $A B A$ synthetic genes in higher plants. The interaction between $A B A$ and sugar signaling continuously promotes the growth and development of plants.

In this study, E. ferox seeds, as the research material, were sampled at four different stages of its development (10, 20, 30, and 40 days after flowering). By using RNA sequencing (RNA-seq) and iTRAQ technology (Fig. 2), we analyzed the mechanism of interaction between ABA and starch biosynthesis. The regulatory mechanisms lay a foundation for improving starch content in plants.

\section{Results}

\section{The differences in starch content and amyloid morphology during the development of $E$. ferox seeds}


Ten to 40 days after flowering, fruit weights of E. ferox showed an increasing trend. The 10-20 day weight gain was the largest (141.3\%), and the increase was reduced after 20-40 days. The total starch content of the seeds increased during seed maturation. The total starch content increased the fastest after 20-30 days of flowering. When the kernels reached maturity at 40 days, the total starch content was as high (62.94\%). Amylopectin and amylose content also increased. However, the amylopectin/amylose ratio was decreased (Fig. 3, Table S1).

Ten days after flowering, the seed cells began to enter initial proliferation. At this time, cell volume was small, amyloid in the cells was low, and the amyloid was spherical and arranged neatly within the cells. The starch granules had irregular polyhedral shapes with sharp edges and corners. With seed development, cell volume expanded, and amyloid volume in the seed increased. When the seed was mature, the amyloid was arranged closely, and the degree of cell filling was increased (Fig. 4).

The above observations are consistent with the results of the determination of the seed starch content. Ten days after flowering, the starch content in the seeds was reduced. During the 10-20 days after flowering, starch accumulated in large amounts, and the content increased rapidly. At 20-25 days after flowering, the seeds gradually matured, and the starch increase was more gradual.

\section{Overview of the quantitative proteomics analysis}

iTRAQ was applied to analyze the proteins extracted from the seeds of E. ferox collected at 10, 20, 30 and 40 days after flowering.Three biological replicates were used to the proteomic analysis (Fig. S1, Table S2).We used liquid-mass coupling (LMS) to analyze the samples labeled by enzymatic hydrolysis.In order to obtain credible protein, the peptide matching error was confined to less than $1 \mathrm{ppm}$. The screening results were as follows: the credible protein 1 screens out 3175 credible proteins; protein 2 screens out 3083 credible proteins; and credible protein 3 screens out 3118 credible proteins .

The v-look up function was used to differentially screen the three results. The t-test was performed on data with three repeats to compare the values in each group, and the difference multiples FC and the pvalues of each comparison group were calculated to determine significant differences. Then, the double standards with 2 times difference multiples and p-value less than 0.05 were used to screen differentially expressed proteins. One hundred fifty-two (20 vs. 10 days), 736 (30 vs. 10 days), 774 (40 vs. 10 day), 460 (30 vs. 20 days), 530 (40 vs. 20 days) and 157 (40 vs. 30 days) DEPs were identified (Fig. S2). The results indicated that with the maturity of $E$. ferox seeds, increasing proteins were involved in the development process, with more proteins involved in the later stages of development than in the early stages (Fig. S3).

\section{Overview of the transcriptomic analysis}

RNA-seq was performed for four groups at 10, 20, 30 and 40 days, and each group included three biological replicates. A total of 4897 DEGs were confirmed among the nine samples at the four developmental stages in E. ferox seeds [32]. KEGG pathway analysis was used to identify the biological roles of DEGs with functional annotation and enrichment modules. According to the KEGG pathway 
enrichment analysis, the DEGs in related modules were enriched in environment information processing, especially those related to plant hormone signal transduction in E. ferox seeds. (Fig. S4).

\section{Comprehensive analysis of the WGCNA network of E. ferox seed RNA-Seq data}

The WGCNA package was used to obtain a comprehensive understanding of DEGs in E. ferox seed at the different developmental stages and to identify important genes that are highly associated with seed starch [33]. All 4897 DGEs were retained for WGCNA. Modules were defined as clusters of highly interconnected genes, and genes within the same cluster had high correlation coefficients among them. This analysis identified 23 distinct modules shown in the dendrogram in Fig. 5a. Different colors represents specific modules containing a cluster of highly correlated genes. Twenty-three modules that correlated with distinct samples due to specific expression profiles were identified (Table S3).

In addition, correlation among different modules was also considered, and 7 broad clades were identified in 14 modules (Fig. 5b). A heat map showed that there was a high degree of correlation among the three black dotted boxes, such as the light green module, dark green module, turquoise module and the royal blue module. $\mathrm{GO}$ analysis in these modules identified series terms that were involved in response to signal transduction and protein phosphorylation, indicating that these clusters may participate in the process of seed development.

Genes in the module were related to starch data. Notably, ME light yellow, ME tan, ME light green and ME brown were highly related and selected for analysis. ABA-signaling regulatory genes were identified as a candidate hub for these modules (Fig. $5 \mathrm{C}$ ). These ABA regulating genes had the highest connectivity in the dataset, indicating that the ABA signaling regulatory network may play a major role in seed starch. These genes included SnRK2, which functions primarily as a positive regulator of ABA signaling. A member of the PYR (pyrabactin resistance)/PYL(PYR1-like)/RCAR (regulatory components of ABA receptor) family of proteins functions as an abscisic acid sensor (Table S4). These results suggest that ABA signaling has an important relationship with starch biosynthesis in E. ferox seeds.

\section{Comparative analysis of transcriptome and proteome data}

To further explore the development of E. ferox seeds, we conducted a correlation analysis between the transcriptomic and quantitative proteomic data (Fig. 6). A total of 4897 DEGs and 3494 DEPs were identified in transcriptome and proteome, respectively, of which 433 members were determined to correlate with transcript-to-protein based on identification. Among the 443 cor-DEGs-DEPs genes, 17 (T2 vs T1), 31 (T3 vs T1), 168 (T4 vs T1) and 51 (T4 vs T2) genes showed the same trend, while 107 (T2 vs T1), 3 (T3 vs T1), 55 (T4 vs T1) and 5 (T4 vs T2 day) genes showed the opposite trend at the two levels (Table S5). We suggest that some of these genes might play important roles in E. ferox seed starch biosynthesis. 
To study the 443 cor-DEGs-DEPs gene, we used GO annotations and KEGG to predict their functions. The results covered a wide range of cellular components, molecular functions and biological processes (Fig. S4). Consistent with the DEG function enrichment and WGCNA, some cor-DEGs-DEPs genes were also related to plant hormone signal transduction. All differentially expressed genes and proteins associated with plant hormones were counted (Fig. 7). We found that these genes, c54854.graph_c0 (EfPYR1), c51120.graph_c0 (EfSnRK2.1) and c47171.graph_c1 (EfSnRK2.2), were differentially expressed during the development of $E$. ferox seeds and the related $A B A$ signaling. These results suggest that these genes regulate $A B A$ signaling and affect starch synthesis in $E$. ferox seeds.

\section{Building a co-expression network}

WGCNA can also be employed to construct gene networks, in which each node represents a gene, and the connecting lines (edges) between genes represent co-expression correlations . EfPYR1, EfSnRK2.1 and EfSnRK2.2 were hub genes that exhibited the most connections in the network as indicated by their high KME (eigengene connectivity) values. We used EfPYR1, EfSnRK2.1 and EfSnRK2.2, representing three nodes, and the thirty gene connecting lines (edges), representing between co-expression correlations, to build a co-expression network (Fig. 8a). The thirty genes were highly expressed in E. ferox seeds development (Fig. 8b). We found that the weight of EfPYR1 was higher than that of EfSnRK2.1 or EfSnRK2.2.

To evaluate the correlation of thirty genes from transcript to protein in E. ferox seed development, the PCC (Pearson correlation coefficient) was calculated (Fig. 8c, Table S6). Among the thirty genes, some genes (c55828.graph_c0, c52934.graph_c0, c5498 1.graph_c2, etc.) showed strong positive correlations, and some genes (c52200.graph_c2, c54936.graph_c0, c53379.graph_c2, etc.) showed negative correlations. The results indicated that these genes play important roles in starch synthesis of seeds during E. ferox seed development.

\section{Identification of the expression patterns of key regulators and changes in hormone content in $E$. ferox seeds}

To analyze key gene expression patterns, three DEGs related to abscisic acid synthesis during the growth and development of E. ferox seeds were selected for qRT-PCR (Fig. 9, Table S7). As shown in Fig. 9, the expression levels of the three cor-DEG-DEP genes, EfPYR1, EfSnRK2.1 and EfSnRK2.2, increases with the growth of $E$. ferox seeds. At the same time, these genes had similar expression patterns to the transcriptome and protein data, indicating that results of the transcriptomic analysis are reliable.

These DEGs were hormone-related and are involved in abscisic acid pathways. The phytohormone abscisic acid (ABA) functions as a crucial signal to promote seed maturation and dormancy. As such, we measured the content of ABA in different $E$. ferox seed development stages. Increased ABA levels were observed with the growth of the E. ferox seeds and maturation (Fig. 9, Table S8). In this study, we found that $\mathrm{ABA}$ was related to starch synthesis. With $E$. ferox seed maturation, $\mathrm{ABA}$ and starch levels increased. These studies further confirmed that reliable prediction of functions of EfPYR1, EfSnRK2.1 and 
EfSnRK2.2 genes regulate starch by ABA during E. ferox seed maturation (Fig. 9). The contents of ABA and starch in $E$. ferox seeds increase in parallel during $E$. ferox seed development.

\section{Discussion}

Sucrose is not only a carbon source for starch synthesis but also a signaling molecule. Alone or in coordination with $A B A$, sucrose can regulate the expression of genes involved in starch synthesis. In sweet cherries (Prunus avium), ABA and starch content increases in the buds during their endodormancy period [34]. The ABA to single-node cuttings of grapevines increased the content of starch and the expression of starch synthesis genes [35]. ABA reportedly plays important roles in starch synthesis during the development of wheat grain [36, 37], barley [38] and rice [39]. In this study, we constructed a dynamic transcriptome and proteome landscape of early E. ferox seed development by sampling 4 time points from 0 days, 10 days, 20 days, 30 days, and 40 days. The dynamic transcriptome and proteome data provided herein clearly demonstrated four key developmental stages within the early seed. We found, by WGCNA analysis, that the increase in starch content was closely related to the ABA hormone in E. ferox seeds. This phenomenon was consistent with previously reported observations. These analyses all proved that ABA promotes starch synthesis to regulate the sink activity and dormancy status of seeds.

The purpose of this study was to investigate the potential regulatory mechanism of starch synthesis in $\mathrm{E}$. ferox seeds. To further identify the key genes involved in these regulatory mechanisms, we performed WGCNA analysis on transcriptome data. We identified three hub genes, EfPYR1, EfSnRK2.1 and EfSnRK2.2, associated with ABA hormone regulation. Further, co-expression analysis was performed in conjunction with proteomic data. Three hub genes were differentially expressed at most different stages during seed formation. In previous reports, $A B A$ was shown to play a crucial role in promoting seed maturation [40-42]. The PYL receptors can bind to $A B A$, which interacts with the type $2 \mathrm{C}$ protein phosphatase (PP2Cs) to form a stable complex, leading to the release of SNF1-related kinase 2 (SnRK2s) from PP2C-SnRK2 complexes [43-48]. Then, SnRK2s are activated to modulate ABA responses [49-53].

These hub genes are generally thought of as not just a simple information flow from the transcriptome to the proteome. There is a complex regulatory network in seed starch synthesis. We identified the abovementioned genes in the seed forming stage, indicating that a network for complex hormonal synthesis and signaling functions to regulate seed starch synthesis (Fig. 10). In a previous report, ABA was demonstrated to play a major role in the sugar signaling network by ABI4 in that it enhanced ApL3 responses to subsequent sugar signals [39], indicating a novel and central role for ABA mediated glucose responses in plants mediated by GIN5 and GIN6/ABI4. Therefore, analogous with the effect of ABA in cereal seeds, our results in starch synthesis suggest that $A B A$ improves $E$. ferox seed starch content by favoring the synthesis of starch.

\section{Conclusions}


In summary, we constructed a complete picture of the molecular dynamics of E. ferox seed maturation by RNA-Seq transcriptome profiling with proteome analysis. We provided comprehensive insight into the regulatory mechanism of $A B A$, which promotes seed starch synthesis during E. ferox development. Furthermore, the contents of $A B A$ in the $E$. ferox seeds increased by enhanced expression of three hub genes, EfPYR1, EfSnRK2.1 and EfSnRK2.2, leading to increases in starch content in E. ferox seeds. Analysis of the comprehensive data set in this study provides a useful genomic resource for $E$. ferox seed maturation research and molecular insights into the ABA and starch regulatory networks in E. ferox seeds.

\section{Methods}

\section{Plant material and sample collection}

The formal identification of the Euryale ferox used by Floar Reipublicae Popularis

Sinicae(http://www.efloras.org/florataxon.aspx?flora_id=2\&taxon_id=200007078): Submerged leaves not prickly; leaf blade sagittate or elliptic, 4-10 cm, base deeply cordate. Floating leaves prickly on petioles and along veins; leaf blade abaxially dark purple and adaxially green, to 1.3(-2.7) $\mathrm{m}$ in diam., subleathery, abaxially sparsely pubescent, adaxially glabrous, base emarginate or sinuate; veins abaxially strongly ribbed; primary veins prickly on both surfaces. Flower to $5 \mathrm{~cm}$ in diam. Peduncle stout, densely prickly. Sepals triangular-ovate, $1-1.5(-3) \mathrm{cm}$, abaxially dense-ly prickly; prickles retrorse. Petals outer purpleviolet fading to inner white, oblong-lanceolate, $1(-2.5) \mathrm{cm}$. Ovary 7-16-loculed, each locule with 6--8 or more ovules. Fruit dark purple, globose, 5-10 cm in diam., spongy, densely prickly. Seeds black, 8 to many, globose, 6-10 mm in diam.; testa thick, rigid. Fl. Jun--Aug.Lakes, ponds. Anhui, Fujian, Guangdong, Guangxi, Guizhou, Hainan, Hebei, Heilongjiang, Henan, Hubei, Hunan, Jiangsu, Jiangxi, Jilin, Liaoning, Nei Mongol, Shaanxi, Shandong, Shanxi, Sichuan, Taiwan, Yunnan, Zhejiang [Bangladesh, India, Japan, Kashmir, Korea, Russia (Far East)].

The Euryale ferox plants was collected from suzhou, China. The collection of this plant materials comply seriously with the Chinese and international guidelines. $E$. ferox (Euryale ferox Salisb.) has not been listed in the appendices I, II and III of the Convention on the Trade in Endangered Species of Wild Fauna and Flora which was validated from Jan 2th, 2017 (https://cites.org/eng/app/appendices.php).The collector had deposited in 2015 with barcode ID: QFNU0018115. (http://www.cvh.ac.cn/en/spm/QFNU/QFNU0018115 ).Guo $\mathrm{CY}$ undertook the formalidentification. Euryale ferox plants were grown in Yangzhou University Aquatic Vegetable Test Base, normal cultivation management. Seeds of E. ferox were collected at 10, 20, 30 and 40 days (stages T1, T2, T3, and T4, respectively) after anthesis. Seed samples with three biological replicates per developmental stage were utilized. All samples were frozen in liquid nitrogen and immediately stored at $-80^{\circ} \mathrm{C}$.

\section{Observation of Amyloid in E. ferox seeds}


Euryale ferox seeds were cut into approximately $5 \mathrm{~mm} \times 5 \mathrm{~mm} \times 5 \mathrm{~mm}$ small blocks, immediately placed in $0.1 \mathrm{~mol} / \mathrm{L}$ glutaraldehyde fixation fluid, refrigerated at 0 to $4{ }^{\circ} \mathrm{C}$, and used to observe the starch grain morphology. Cut kernels were removed from glutaraldehyde fixative before observation and washed 3-4 times with double distilled water. Then, $30 \%, 50 \%, 70 \%, 80 \%, 90 \%, 95 \%, 100 \%$ and then $100 \%$ (addition of anhydrous $\mathrm{Na}_{2} \mathrm{SO}_{4}$ ) ethanol was added for dehydration and drying after the completion of dehydration (CPD-300 type critical point dryer). After drying, the observed surface of the Euryale ferox seed was placed onto the stage, face up, and the surface was sprayed with gold in an SCD 500 ion sputter. Finally, the amyloplast and starch granule structure were subjected to S-4800Il field emission scanning electron microscopy (FESEM) for morphological observation and imaging.

\section{Starch content determination}

The total starch content, amylose content, amylopectin content, and amylose and amylopectin content ratios of Euryale ferox seeds were determined using the Megazyme Total Starch Kit (K-TSTA 09/14, Megazyme International Ireland Ltd.) and the Megazyme Straight Ratio Kit (K-AMYL 09/14, Megazyme International Ireland Ltd.).

Total starch content

Mill cereal, plant or food products were passed through a $0.5 \mathrm{~mm}$ screen. An accurate weight of $\sim 100$ $\mathrm{mg}$ of test sample, in duplicate (one as a sample blank), was placed into Corning culture tubes $(16 \times 120$ $\mathrm{mm})[\mathrm{C}(\mathrm{q})]$, and the exact weights were recorded. The tubes were tapped so that the samples dropped to

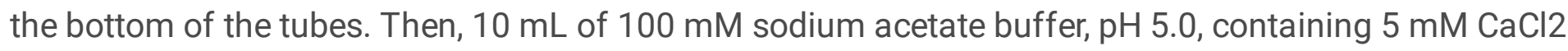
$[B(a)]$ was added to each tube using a Brand Bottle-top dispensette $[C(m)]$. The tubes were vigorously stirred on a vortex mixer for $5 \mathrm{~s}$. Next, $0.1 \mathrm{~mL}$ of undiluted thermostable a-amylase [A(1)] (Megazyme cat. no. E-BSTAA) was added to one of the tubes using a HandyStep ${ }^{\circledR}$ dispenser [C(I)] with a $5 \mathrm{~mL}$ tip. The second tube (sample blank) received $0.1 \mathrm{~mL}$ of $100 \mathrm{mM}$ sodium acetate buffer ( $\mathrm{pH}$ 5.0) [B(a)]. The tubes $[C(j)]$ were vortexed for $3 \mathrm{~s}$, the tubes were loosely capped and immediately transferred to a boiling water bath. After approx. $2 \mathrm{~min}$, tube caps were tightened, and the contents were vigorously mixed on a vortex mixer. After an additional 5 and $10 \mathrm{~min}$, tube contents were vortexed again for $5 \mathrm{~s}$ and returned to the boiling water bath. After 15 min (from addition of a-amylase), the tubes were removed from the boiling water bath, and the contents were vigorously mixed for $5 \mathrm{~s}$ on a vortex mixer. The tubes were then placed in a water bath at $50^{\circ} \mathrm{C}$ and allowed to equilibrate to temperature for $5 \mathrm{~min}$. Then, $0.1 \mathrm{~mL}$ of undiluted AMG [A(2)] (Megazyme cat. no. E-AMGDF; $3,300 \mathrm{U} / \mathrm{mL}$ ) was added to the sample tube using a HandyStep ${ }^{\circledR}$ dispenser with a $5 \mathrm{~mL}$ tip and vortexed for $3 \mathrm{~s}$. To the second tube (the sample blank), 0.1 $\mathrm{mL}$ of $100 \mathrm{mM}$ sodium acetate buffer $(\mathrm{pH} 5.0)$ [B(a)] was added. The tubes were incubated at $50^{\circ} \mathrm{C}$ for 30 min with no further mixing. Then, the tubes were removed from the water bath and allowed to cool to room temperature for $10 \mathrm{~min}$. The tubes were inverted a few times to ensure that the condensed water on the inside of the lid was mixed with liquid in the tube. Then, $2.0 \mathrm{~mL}$ of each solution (sample and sample blank) was transferred to microfuge tubes [C(o)] that were centrifuged at 13,000 rpm for $5 \mathrm{~min}$ (the remaining $8.2 \mathrm{~mL}$ of incubation solution was retained; refer to the NOTE below). Using a Gilson Pipetman 
dispenser, a $1.0 \mathrm{~mL}$ aliquot of the supernatants was accurately transferred to $12 \times 120 \mathrm{~mm}$ tubes containing $4 \mathrm{~mL}$ of $100 \mathrm{mM}$ sodium acetate buffer ( $\mathrm{pH}$ 5.0), and the contents were mixed. Then, $0.1 \mathrm{~mL}$ aliquots of each sample were transferred in duplicate to the bottoms of $16 \times 120 \mathrm{~mm}$ glass test tubes. A single $0.1 \mathrm{~mL}$ aliquot of the blank sample was also transferred to a $16 \times 120 \mathrm{~mm}$ glass test tube, and 3.0 $\mathrm{mL}$ of GOPOD reagent was added with subsequent incubation of the solutions at $50^{\circ} \mathrm{C}$ for $20 \mathrm{~min}$. The absorbance was then measured at $510 \mathrm{~nm}$ and compared with the reagent blank.

Amylopectin content and amylose/amylopectin content ratios

\section{Starch Pretreatment}

The starch or flour samples were accurately weighed $(20-25 \mathrm{mg}$ to the nearest $0.1 \mathrm{mg})$ into $10 \mathrm{~mL}$ screw capped Kimax® sample tubes. The sample weight was recorded to the nearest $0.1 \mathrm{mg}$. To the tube, $1 \mathrm{~mL}$ DMSO was added while gently stirring at low speed on a vortex mixer. The tube was capped, and the tube contents were heated in a boiling water bath until the sample was completely dispersed (approx. $1 \mathrm{~min}$ ) until no gelatinous lumps of starch remained. The contents of the sealed tubes were vigorously mixed at high speed on a vortex mixer, and the tubes were placed in a boiling water bath and heated it for $15 \mathrm{~min}$ with intermittent high-speed stirring on a vortex mixer The tubes were stored at room temperature for approx. $5 \mathrm{~min}$, and $2 \mathrm{~mL}$ of $95 \%(\mathrm{v} / \mathrm{v})$ ethanol was added with continuous stirring on a vortex mixer. An additional $4 \mathrm{~mL}$ of ethanol was added, and the tubes were capped and inverted to mix. A starch precipitate formed. The tubes were allowed to stand for $15 \mathrm{~min}$ (or overnight if desired). The tubes were centrifuged at 2,000 $\mathrm{g}$ for $5 \mathrm{~min}$, the supernatants were discarded and the tubes were drained on tissue paper for 10 min until all of the ethanol was removed. The pellet was used in subsequent amylose and starch measurements. A volume of $2 \mathrm{~mL}$ DMSO was added to the starch pellet with gentle vortex mixing. The tubes were placed in a boiling water bath for $15 \mathrm{~min}$ and mixed occasionally to ensure that there were no gelatinous lumps. 7. Upon removing tubes from the boiling water bath, $4 \mathrm{~mL}$ Con A solvent (Buffer 3; page 4) immediately added and mixed thoroughly, and then the tube contents were completely transferred (by repeated washing with Con A solvent) to a $25 \mathrm{~mL}$ volumetric flask. The volume was diluted with Con A solvent (this is Solution A). When necessary, this solution was filtered through Whatman ${ }^{\circledR}$ No. 1 filter paper (this step was necessary for the whole flour samples).

B. Con A Precipitation of Amylopectin and Determination of Amylose A total of $1.0 \mathrm{~mL}$ Solution A was transferred to a $2.0 \mathrm{~mL}$ Eppendorf ${ }^{\circledR}$ microfuge tube. A volume of 0.50 $\mathrm{mL}$ Con A solution (bottle 1 ) was added, and the tube was capped and gently mixed by repeated inversion. The tube was allowed to stand for $1 \mathrm{~h}$ at room temperature. The tube was centrifuge at 14,000 $g$ for $10 \mathrm{~min}$ in a microfuge at room temperature. A volume of $1 \mathrm{~mL}$ of the supernatant was transferred to a $15 \mathrm{~mL}$ centrifuge tube. A total of $3 \mathrm{~mL}$ of $100 \mathrm{mM}$ sodium acetate buffer, $\mathrm{pH} 4.5$, was added. This buffer reduced the $\mathrm{pH}$ to $\sim 5$. The contents were mixed, lightly stoppered (with a marble) and heated in a boiling water bath for $5 \mathrm{~min}$ to denature the Con $\mathrm{A}$. The tube was placed in a water bath at $40^{\circ} \mathrm{C}$ and allowed to equilibrate for $5 \mathrm{~min}$. A volume of $0.1 \mathrm{~mL}$ of a amyloglucosidase/a-amylase enzyme mixture (page 3; solution 2) was added and incubated at $40^{\circ} \mathrm{C}$ for $30 \mathrm{~min}$. The tube was centrifuged at $2,000 \mathrm{~g}$ for $5 \mathrm{~min}$. To $1.0 \mathrm{~mL}$ aliquots of the supernatant, $4 \mathrm{~mL}$ of GOPOD Reagent (Reagent B) was added. The 
solution was incubated at $40^{\circ} \mathrm{C}$ for $20 \mathrm{~min}$, and the Reagent Blank and the D-Glucose Controls were incubated concurrently The absorbance of each sample and the D-glucose controls were read at $510 \mathrm{~nm}$ and compared with the reagent blank.

\section{Protein extraction, iTRAQ labeling and LC-ESI mass spectrometry (MS)/MS analysis}

All analyses were performed by a Triple TOF 5600 mass spectrometer (SCIEX, USA) equipped with a Nanospray III source (SCIEX, USA). The samples were loaded by a capillary C18 trap column $(3 \mathrm{~cm} \times 100$ $\mu \mathrm{m})$ and then separated by a C18 column $(15 \mathrm{~cm} \times 75 \mu \mathrm{m})$ on an Eksigent nanoLC-1D plus system (SCIEX, USA). The flow rate was $300 \mathrm{~nL} / \mathrm{min}$, and the linear gradient was $90 \mathrm{~min}$ (from $5-85 \%$ B over 67 min; mobile phase $A=2 \% A C N / 0.1 \% F A$ and $B=95 \% A C N / 0.1 \% F A)$.

The data were acquired with a $2.4 \mathrm{kV}$ ion spray voltage, 35 psi curtain gas, 5 psi nebulizer gas, and an interface heater temperature of $150^{\circ} \mathrm{C}$. The MS scanned between 400 and 1500 with an accumulation time of $250 \mathrm{~ms}$. For IDA, $30 \mathrm{MS} / \mathrm{MS}$ spectra (80 ms each, mass range $100-1500$ ) of MS peaks above intensity 260 and with a charge state of between 2 and 5 were acquired. A rolling collision energy voltage was used for the CID fragmentation for the acquired MS/MS spectra. The mass was dynamically excluded for $22 \mathrm{~s}$.

\section{WGCNA Network Analysis}

We utilized the Euryale ferox seed Illumina RNA-seq data that were previously generated and analyzed by Liu et al. The gene co-expression network using differentially expressed genes was constructed using the WGCNA package in R [41]. A total of 23 different modules were derived as described. Module hub genes were used as seed nodes to extract the gene co-expression network, and the resulting gene-gene interactions were used to visualize the subnetworks using Cytoscape. In standard WGCNA networks, the power was set to 6 , minModuleSize was set to 30 , and initial clusters were merged on eigengenes. The merge CutHeight value was set to 0.25 across all networks. The total connectivity was calculated for all genes in each network.

\section{Function annotations}

The DEGs or DEPs were mapped to Gene Ontology (GO) terms and Kyoto Encyclopedia of Genes and Genomes (KEGG) pathways (http://www. genome.jp/kegg/).

\section{Measurements of hormone content}

The endogenous hormone contents in Euryale ferox seeds were measured. Each sample was prepared by three replicate samples. High-performance liquid chromatography-mass spectrometry was used to measure hormone. (AB 5500, Beijing, China) following the protocol described previously [54].

\section{Quantitative real-time PCR analysis}


Total RNA was extracted from triplicate samples from the four developmental stages of $E$. ferox seeds (total of 12 samples) using an RNA kit (RNA simply Total RNA Kit, Tiangen, Beijing, China) according to the manufacturer's instructions. Five micrograms of each sample was reverse transcribed into cDNA using the Prime Script RT reagent Kit (TaKaRa). Gene-specific primers for the three genes sequences were designed using Primer Premier 5 software. The $\beta$-Actin gene was amplified with forward primer 5 'GACTCTGGTGATGGTGT-3' and reverse primer 5'-CACTTCATGATG GAGTTGT-3'. The amplifications were performed in $20 \mu \mathrm{l}$ reactions consisting of $10 \mu \mathrm{l} 2 \times$ SYBR® Premix EX Taqll (Tli RNaseHPlus) (TaKaRa, Dalian, China), $2.0 \mu \mathrm{l}$ of a mixture of the forward and reverse primers, $2.0 \mu \mathrm{l}$ cDNA template, and $6.0 \mu \mathrm{l}$ sterile $\mathrm{ddH}_{2} \mathrm{O}$. A detection System (Bio-Rad, Hercules, CA, USA) was used with the following cycling parameters: $95^{\circ} \mathrm{C}$ for $3 \mathrm{~min}$, followed by 39 cycles of $95^{\circ} \mathrm{C}$ for $30 \mathrm{~s}$ and Tm for $30 \mathrm{~s}$.

\section{Abbreviations}

WGCNA

Weighted Gene Co-expression Network Analysis

DEG

Differentially expressed gene

DEP

Differentially expressed protein

FPKM

Fragments per kilobase of exon per million fragments mapped

\section{Declarations}

\section{Availability of data and materials}

Not applicable.

\section{Ethics approval and consent to participate}

Not applicable.

\section{Consent for publication}

Not applicable.

\section{Competing interests}

The authors declare that they have no competing interests.

\section{Funding}


This work was supported by the China Agriculture Research System(CARS-24) and National Natural Science Foundation of China (no.31902002). The funding bodies had no role in the design, collection, and analysis, interpretation of data or in writing the manuscript.

\section{Acknowledgments}

Not applicable.

\section{Author contributions}

W. conceived and designed the experimental design. X.L1(Xiang Li)., X.X., X.L2(Xian Liu)., and X.Z. contributed to the experimental work. L. L.contributed to the interpretation of the results and coordinated the study. All the authors read and approved the final manuscript.

\section{References}

1.

Zhiwu Q, Lei P, Weidong K, Yi D. Polymorphic microsatellite markers in Euryale ferox Salisb.

(Nymphaeaceae). Molecular Ecology Resources. 2010;9(1):330-2.

2.

China MI. Compendium of Materia Medica. 2014.

3.

Zhao HR, Zhao SX, Sun CQ, Guillaume D. Glucosylsterols in extracts of Euryale ferox identified by high resolution NMR and mass spectrometry. J Lipid Res. 1989;30(10):1633-7.

4.

Zhao H,., Zhao S, Guillaume, Sun D. C,. New cerebrosides from Euryale ferox. J Nat Prod. 1994;57(1):13841.

5 .

Das S, Der P, Raychaudhuri U, Maulik N, Das DK. The Effect of Euryale Ferox (Makhana), an Herb of Aquatic Origin, on Myocardial Ischemic Reperfusion Injury. Molecular Cellular Biochemistry. 2006;289(12):55-63.

6.

Emes MJ, Bowsher CG, Hedley C, Burrell MM, Scrase-Field ESF, Tetlow IJ. Starch synthesis and carbon partitioning in developing endosperm. J Exp Bot. 2003;54(382):569-75.

7.

Tetlow IJ, Morell MK, Emes MJ. Recent developments in understanding the regulation of starch metabolism in higher plants. J Exp Bot. 2004;55(406):2131-45.

8.

Duan M, Sun SSM. Profiling the Expression of Genes Controlling Rice Grain Quality. Plant Mol Biol. 2005;59(1):165.

9. 
Ohdan T, Francisco PJT, Hirose T, Terao T, Satoh H, Nakamura Y. Expression profiling of genes involved in starch synthesis in sink and source organs of rice. J Exp Bot. 2005;56(422):3229-44.

10.

Sasaki H, Edo E, Uehara N, Ishimaru T, Kawamitsu Y, Suganuma S, Ueda D, Ohsugi R. Effect of sucrose on activity of starch synthesis enzymes in rice ears in culture. Physiol Plant. 2010;124(3):301-10.

11.

Jiang D, Cao W, Dai T, Jing Q. Activities of key enzymes for starch synthesis in relation to growth of superior and inferior grains on winter wheat (Triticum aestivum L.) spike. Plant Growth Regul. 2003;41(3):247-57.

12.

Kato T, Dai S, Taniguchi A. Activities of enzymes for sucrose-starch conversion in developing endosperm of rice and their association with grain filling in extra-heavy panicle types. Plant Production Science. 2007;10(4):442-50.

13.

Panda BB, Kariali E, Panigrahi R, Mohapatra PK. High ethylene production slackens seed filling in compact panicled rice cultivar. Plant Growth Regul. 2009;58(2):141-51.

14.

Tang T, Xie H, Wang Y, Lü B, Liang J. The effect of sucrose and abscisic acid interaction on sucrose synthase and its relationship to grain filling of rice (Oryza sativa L.). J Exp Bot. 2009;60(9):2641. 15.

Ishimaru T, Hirose T, Matsuda T, Goto A, Takahashi K, Sasaki H, Terao T, Ishii R, Ohsugi R, Yamagishi T. Expression patterns of genes encoding carbohydrate-metabolizing enzymes and their relationship to grain filling in rice (Oryza sativa L.): comparison of caryopses located at different positions in a panicle. Plant Cell Physiology. 2005;46(4):620-8.

16.

Yang J, Zhang J, Wang Z, Liu K, Wang P. Post-anthesis development of inferior and superior spikelets in rice in relation to abscisic acid and ethylene. J Exp Bot. 2006;57(1):149-60.

17.

Hao Z, Tan G, Yang L, Yang J, Zhang J, Zhao B. Hormones in the grains and roots in relation to postanthesis development of inferior and superior spikelets in japonica/indica hybrid rice. Plant Physiology Biochemistry. 2009;47(3):195-204.

18.

Rook F, Hadingham YH, Bevan MW. Sugar and ABA response pathways and the control of gene expression. Plant Cell Environment. 2010;29(3):426-34.

19.

Arenas HF, Arroyo A, Sheen L, Leon J. P: Analysis of Arabidopsis glucose insensitive mutants, gin5 and gin6, reveals a central role of the plant hormone ABA in the regulation of plant vegetative development by sugar. Genes Dev. 2000;14(16):2085-96.

20. 
Koßmann J, Visser RGF, Müller-Röber B, Willmitzer L, Sonnewald U. Cloning and expression analysis of a potato cDNA that encodes branching enzyme evidence for co-expression of starch biosynthetic genes. Molecular General Genetics Mgg. 1991;230(1-2):39-44.

21.

Morell MK, Bloom M,., Knowles V, Preiss. J,. Subunit Structure of Spinach Leaf ADPglucose Pyrophosphorylase. Plant Physiol. 1987;85(1):182-7.

22.

Smith-White BJ, Preiss J. Comparison of proteins of ADP-glucose pyrophosphorylase from diverse sources. J Mol Evol. 1992;34(5):449-64.

23.

Stark DM, Timmerman KP, Barry GF, Preiss J, Kishore GM. Regulation of the Amount of Starch in Plant Tissues by ADP Glucose Pyrophosphorylase. Science. 1992;258(5080):287-92.

24.

Sweetlove LJ, Mullerrober B, Willmitzer L, Hill SA. The contribution of adenosine 5'-diphosphoglucose pyrophosphorylase to the control of starch synthesis in potato tubers. Planta. 1999;209(3):330-7. 25.

Bae JM, Liu JR. Molecular cloning and characterization of two novel isoforms of the small subunit of ADPglucose pyrophosphorylase from sweet potato. Molecular General Genetics Mgg. 1997;254(2):17985.

26.

Müller-R?Ber BT, Kossmann J,., Hannah LC, Willmitzer L, Sonnewald. U,. One of two different ADP-glucose pyrophosphorylase genes from potato responds strongly to elevated levels of sucrose. Molecular General Genetics Mgg. 1990;224(1):136-46.

27.

Sokolov L, Dejardin A, Kleczkowski L. Sugars and light/dark exposure trigger differential regulation of ADP-glucose pyrophosphorylase genes in Arabidopsis thaliana (thale cress). Biochem J. $1998 ; 336(3): 681-7$.

28.

Villand P, Olsen O, Kleczkowski LA. Molecular characterization of multiple cDNA clones for ADP-glucose pyrophosphorylase from Arabidopsis thaliana. Plant Mol Biol. 1993;23(6):1279-84.

29.

Yoshida KT, Fujiwara T, Naito S. The synergistic effects of sugar and abscisic acid on myo-inositol-1phosphate synthase expression. Physiol Plant. 2002;114(4):581-7.

30.

Arenashuertero F, Arroyo A, Zhou L, Sheen J, Leon P. Analysis of Arabidopsis glucose insensitive mutants, gin5 and gin6, reveals a central role of the plant hormone ABA in the regulation of plant vegetative development by sugar. Genes Dev. 2000;14(16):2085-96.

31.

Cheng W, Endo A, Zhou L, Penney J, Chen H, Arroyo A, Leon P, Nambara E, Asami T, Seo M. A Unique Short-Chain Dehydrogenase/Reductase in Arabidopsis Glucose Signaling and Abscisic Acid Biosynthesis 
and Functions. Plant Cell. 2002;14(11):2723-43.

32.

Liu X, He Z, Yin Y, Xu X, Wu W, Li L. Transcriptome sequencing and analysis during seed growth and development in Euryale ferox Salisb. BMC Genom. 2018;19(1):343.

33.

Langfelder P, Horvath S. WGCNA: an R package for weighted correlation network analysis. BMC Bioinformatics. 2008;9(1):559-9.

34.

Fadón E, Herrero M, Rodrigo J. Dormant Flower Buds Actively Accumulate Starch over Winter in Sweet Cherry. Front Plant Sci. 2018;9:171-.

35.

Rubio S, Noriega X, Perez FJ. ABA promotes starch synthesis and storage metabolism in dormant grapevine buds. Journal of Plant Physiology 2019:1-8.

36.

Yang J, Zhang J, Wang Z, Xu G, Zhu Q. Activities of Key Enzymes in Sucrose-to-Starch Conversion in Wheat Grains Subjected to Water Deficit during Grain Filling. Plant Physiol. 2004;135(3):1621-9. 37.

Yang J, Zhang J, Liu K, Wang Z, Liu L. Abscisic acid and ethylene interact in wheat grains in response to soil drying during grain filling. New Phytol. 2006;171(2):293-303.

38.

Seiler C, Harshavardhan VT, Rajesh K, Reddy PS, Strickert M, Rolletschek H, Scholz U, Wobus U, Sreenivasulu N. ABA biosynthesis and degradation contributing to ABA homeostasis during barley seed development under control and terminal drought-stress conditions. J Exp Bot. 2011;62(8):2615-32. 39.

Zhu G, Ye N, Yang J, Peng X, Zhang J. Regulation of expression of starch synthesis genes by ethylene and $\mathrm{ABA}$ in relation to the development of rice inferior and superior spikelets. J Exp Bot. 2011;62(11):3907-16.

40.

Finkelstein RR, Gampala SSL, Rock CD. Abscisic Acid Signaling in Seeds and Seedlings. Plant Cell. 2002;14:15.

41.

Finkelstein RR, Reeves W, Ariizumi T, Steber CM. Molecular Aspects of Seed Dormancy. Annu Rev Plant Biol. 2008;59(1):387-415.

42.

Gubler F, Millar AA, Jacobsen JV. DORMANCY RELEASE. ABA AND PRE-HARVEST SPROUTING. Curr Opin Plant Biol. 2005;8(2):183-7.

43.

Yue M, Izabela S, Arthur K, Danièle M, Yi Y, Alexander C, Erwin G. Regulators of PP2C phosphatase activity function as abscisic acid sensors. Science. 2009;324(5930):1064-8.

44. 
Miyazono K, Miyakawa T, Sawano Y, Kubota K, Kang H, Asano A, Miyauchi Y, Takahashi M, Zhi Y, Fujita Y. Structural basis of abscisic acid signalling. Nature. 2009;462(7273):609-14.

45 .

Nishimura N, Hitomi K, Arvai AS, Rambo RP, Hitomi C, Cutler SR, Schroeder JI, Getzoff ED. Structural mechanism of abscisic acid binding and signaling by dimeric PYR1. Science. 2009;326(5958):1373-9. 46.

Park S, Fung P, Nishimura N, Jensen DR, Fujii H, Zhao Y, Lumba S, Santiago J, Rodrigues A, Chow TF. Abscisic Acid Inhibits Type 2C Protein Phosphatases via the PYR/PYL Family of START Proteins. Science. 2009;324(5930):1068-71.

47.

Santiago J, Dupeux F, Round A, Antoni R, Park S, Jamin M, Cutler SR, Rodriguez PL, Marquez JA. The abscisic acid receptor PYR1 in complex with abscisic acid. Nature. 2009;462(7273):665-8. 48.

Cutler SR, Rodriguez PL, Finkelstein RR, Abrams SR. Abscisic Acid: Emergence of a Core Signaling Network. Annu Rev Plant Biol. 2010;61(1):651-79.

49.

Kobayashi Y, Murata M, Minami H, Yamamoto S, Kagaya Y, Hobo T, Yamamoto A, Hattori T. Abscisic acidactivated SNRK2 protein kinases function in the gene-regulation pathway of ABA signal transduction by phosphorylating ABA response element-binding factors. Plant J. 2005;44(6):939-49.

50 .

Furihata T, Maruyama K, Fujita Y, Umezawa T, Yoshida R, Shinozaki K, Yamaguchishinozaki K. Abscisic acid-dependent multisite phosphorylation regulates the activity of a transcription activator AREB1. Proc Natl Acad Sci USA. 2006;103(6):1988-93.

51.

Fujii H, Verslues PE, Zhu J. Identification of Two Protein Kinases Required for Abscisic Acid Regulation of Seed Germination, Root Growth, and Gene Expression in Arabidopsis. Plant Cell. 2007;19(2):485-94. 52.

Fujii H, Zhu J. Arabidopsis mutant deficient in 3 abscisic acid-activated protein kinases reveals critical roles in growth, reproduction, and stress. Proc Natl Acad Sci USA. 2009;106(20):8380-5. 53.

Nakashima K, Fujita Y, Kanamori N, Katagiri T, Umezawa T, Kidokoro S, Maruyama K, Yoshida T, Ishiyama K, Kobayashi M. Three Arabidopsis SnRK2 protein kinases, SRK2D/SnRK2.2, SRK2E/SnRK2.6/OST1 and SRK2I/SnRK2.3, involved in ABA signaling are essential for the control of seed development and dormancy. Plant Cell Physiology. 2009;50(7):1345-63.

54.

Pin PA, Benlloch R, Bonnet D, Wremerthweich E, Kraft T, Gielen J, Nilsson O. An Antagonistic Pair of FT Homologs Mediates the Control of Flowering Time in Sugar Beet. Science. 2010;330(6009):1397-400.

\section{Figures}




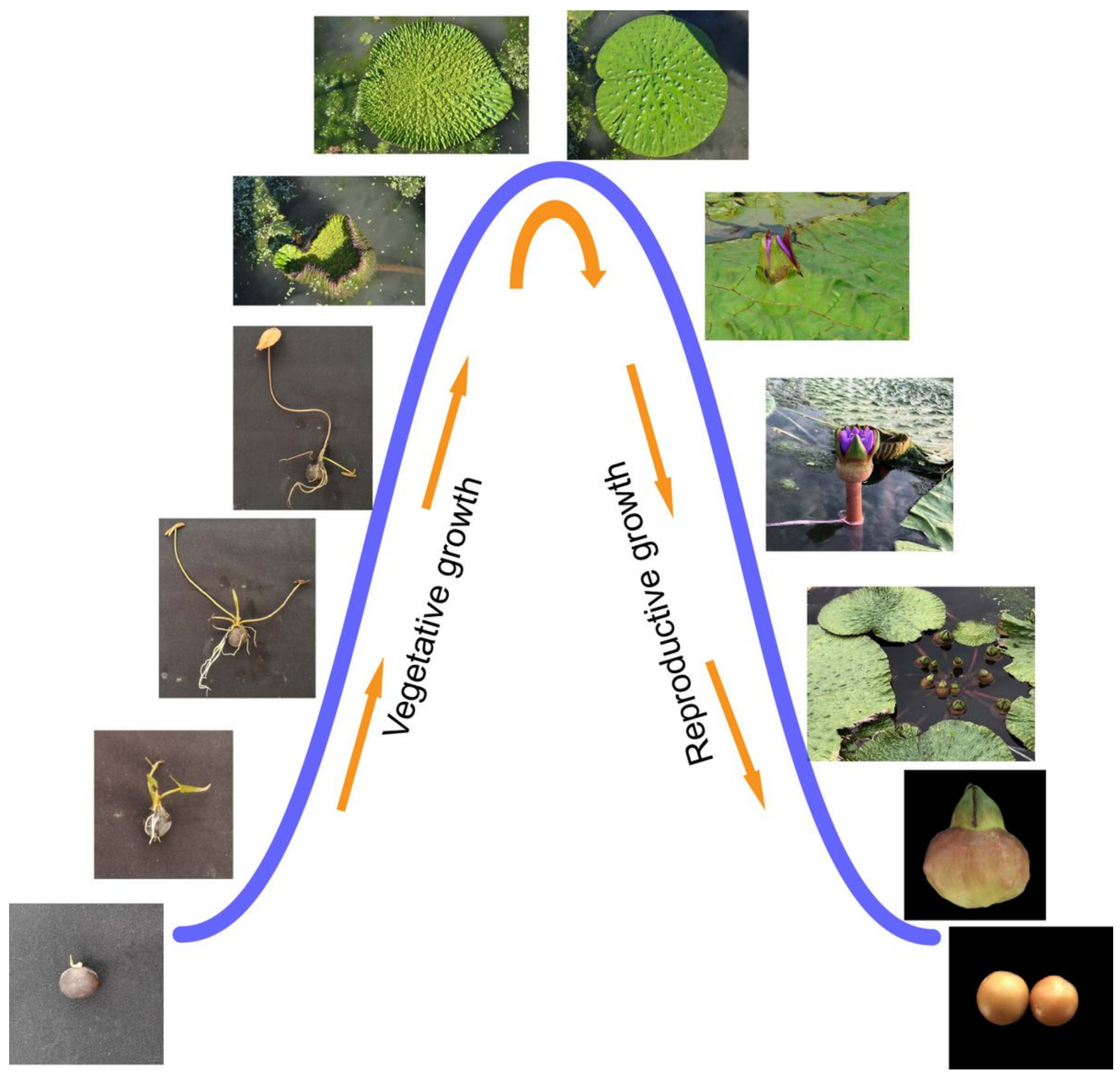

Figure 1

Growth and development of Euryale ferox. 


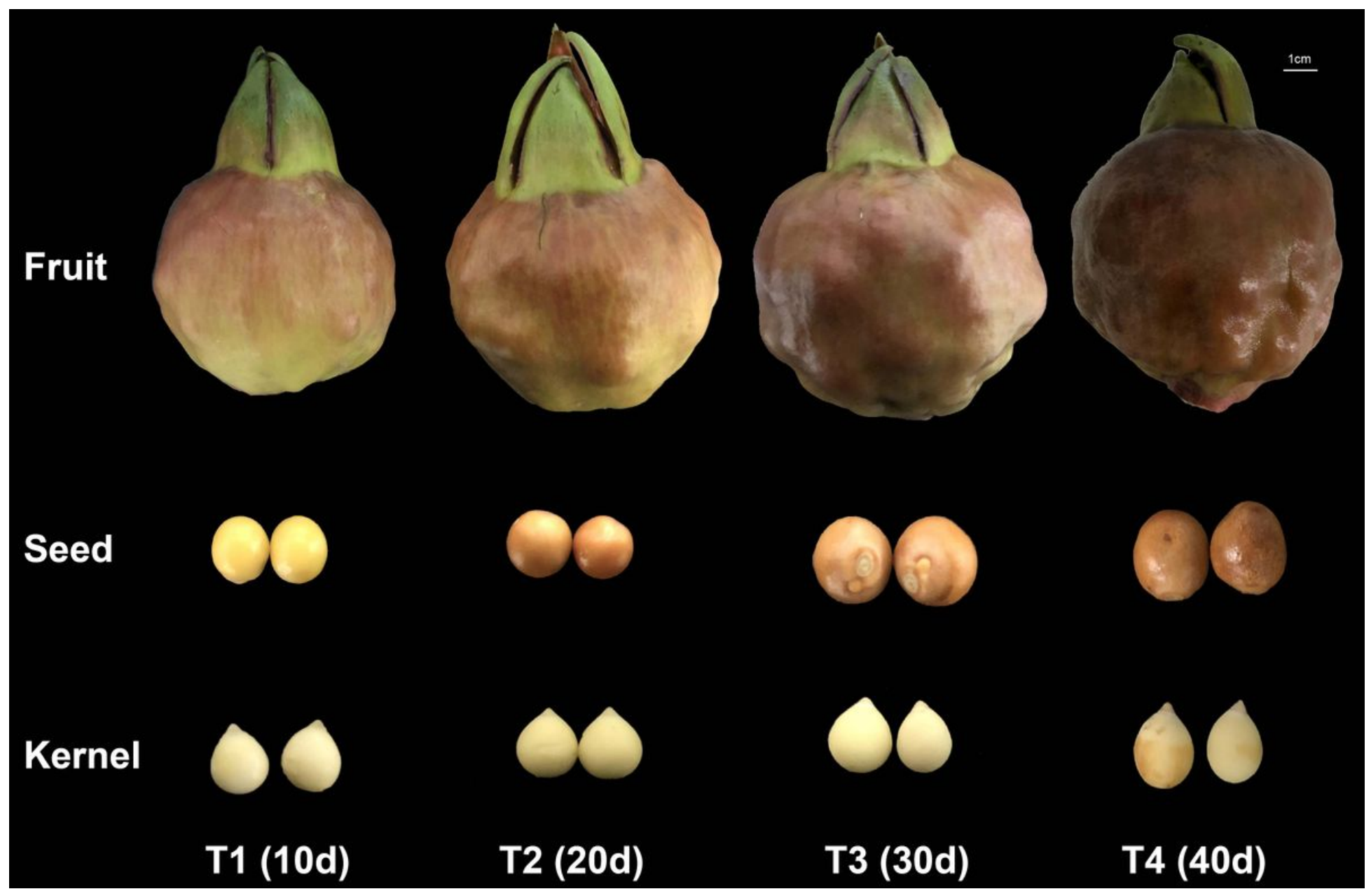

Figure 2

Euryale ferox fruit, seed and kernel during four developmental stages (T1, T2, T3 and T4).
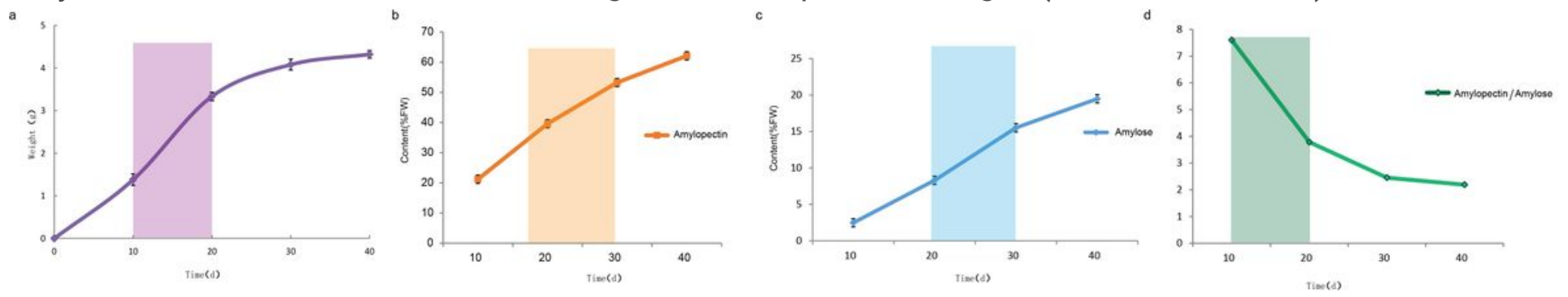

Figure 3

Changes in Euryale ferox seeds during four development stages. (a) Seed weight; (b) Amylopectin content; (c) Amylose content; (d) Ratio of amylopectin to amylose content. 
$\mathrm{T} 1$
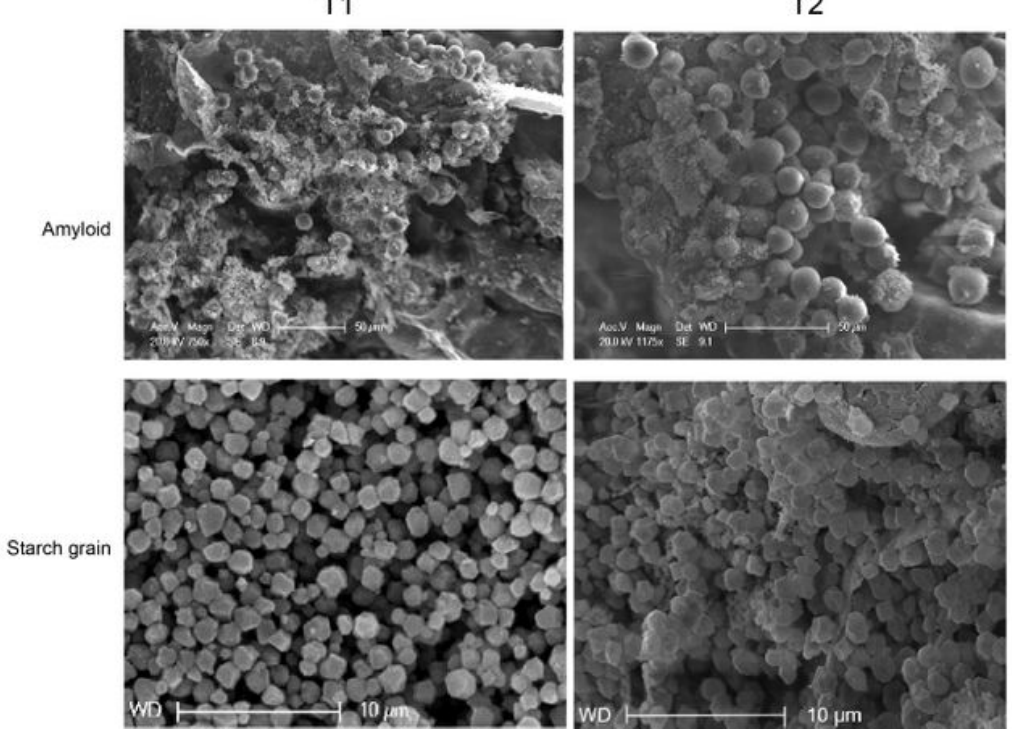

T3
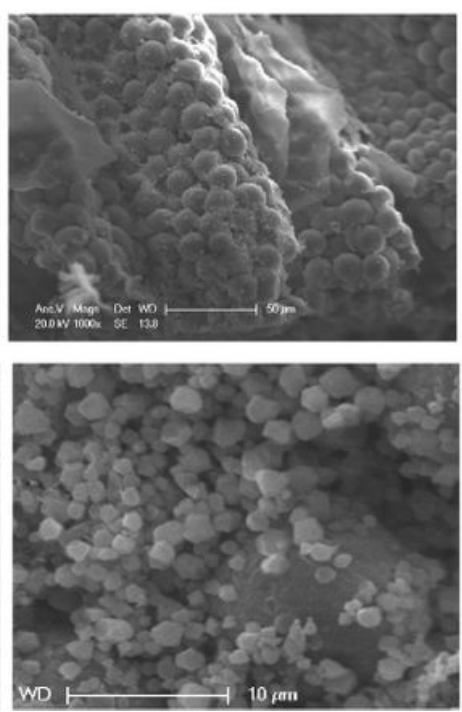

T4
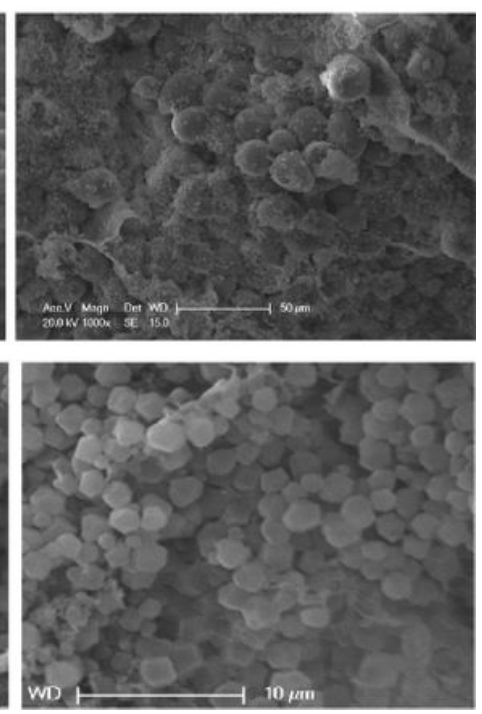

Figure 4

Changes in amyloids and starch grains in seed development in Euryale ferox seeds. 


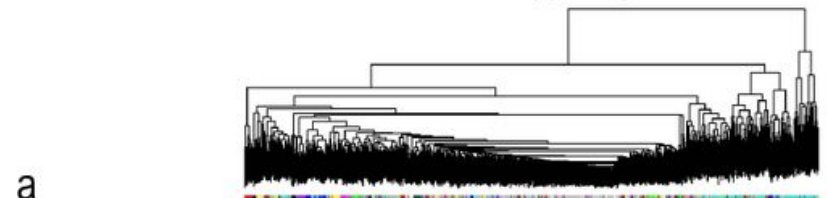

a

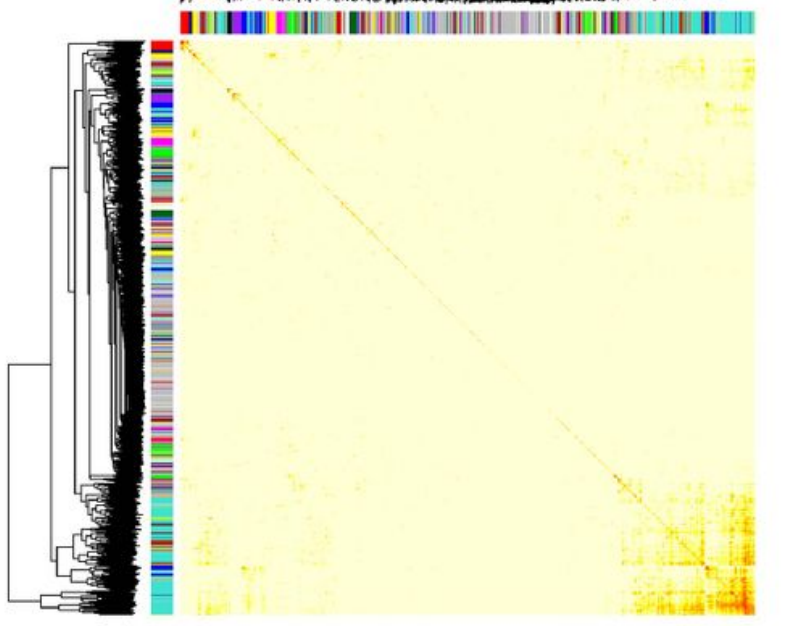

C

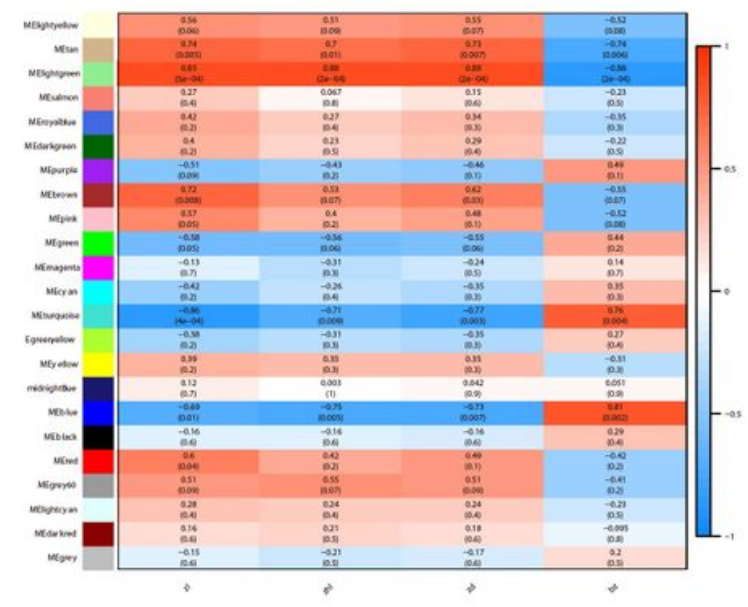

b
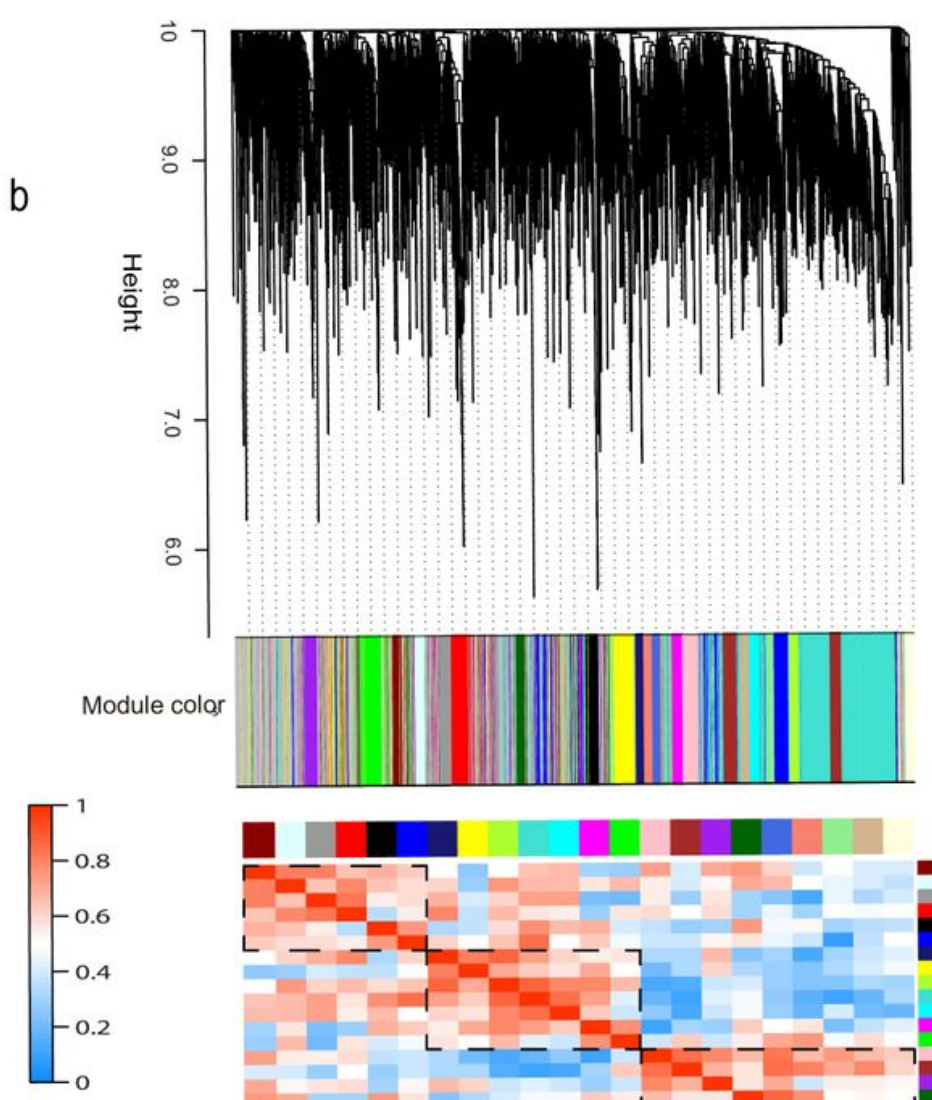

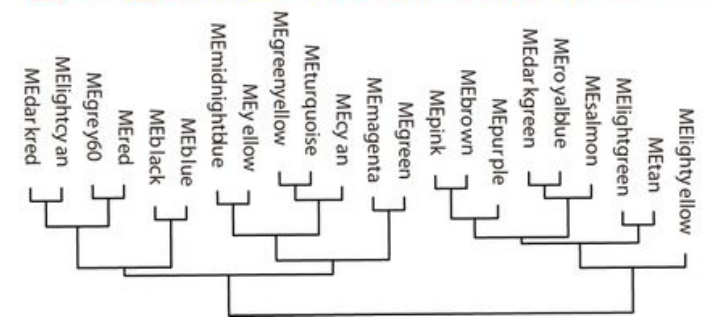

\section{Figure 5}

WGCNA of genes at each Euryale ferox seed developmental stage. (a) Interaction patterns among genes; (b) Hierarchical cluster tree showing co-expression modules identified by WGCNA. The major tree branches constitute 23 modules, labeled with different colors. (c) Module-starch association. Each row corresponds to a module, labeled with a color as in (a).
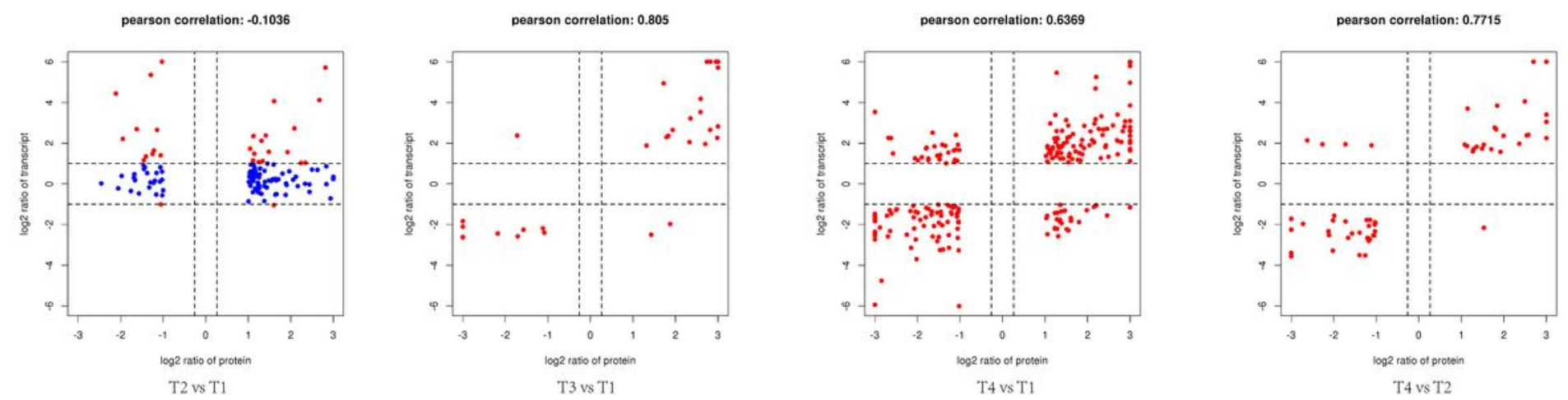
Figure 6

Correlations between protein and messenger ribonucleic acid (mRNA) expression. The $x$-axis represents protein expression levels, and the $y$-axis represents gene expression levels. Scatterplots and correlation coefficients between differentially expressed proteins (DEPs) and differently expressed genes (DEGs).

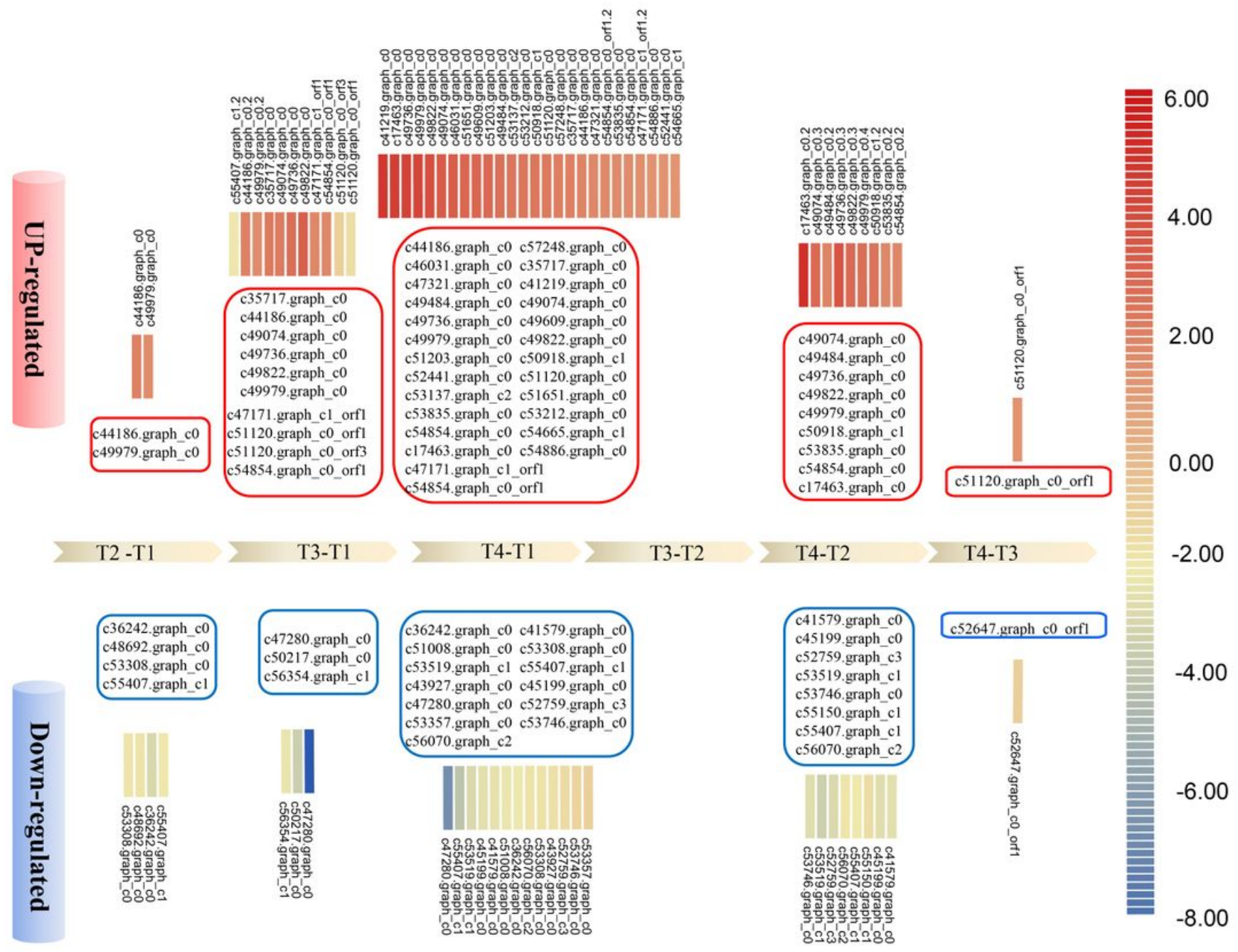

Figure 7

DEPs and DEGs associated with hormones during development of Euryale ferox seeds. 

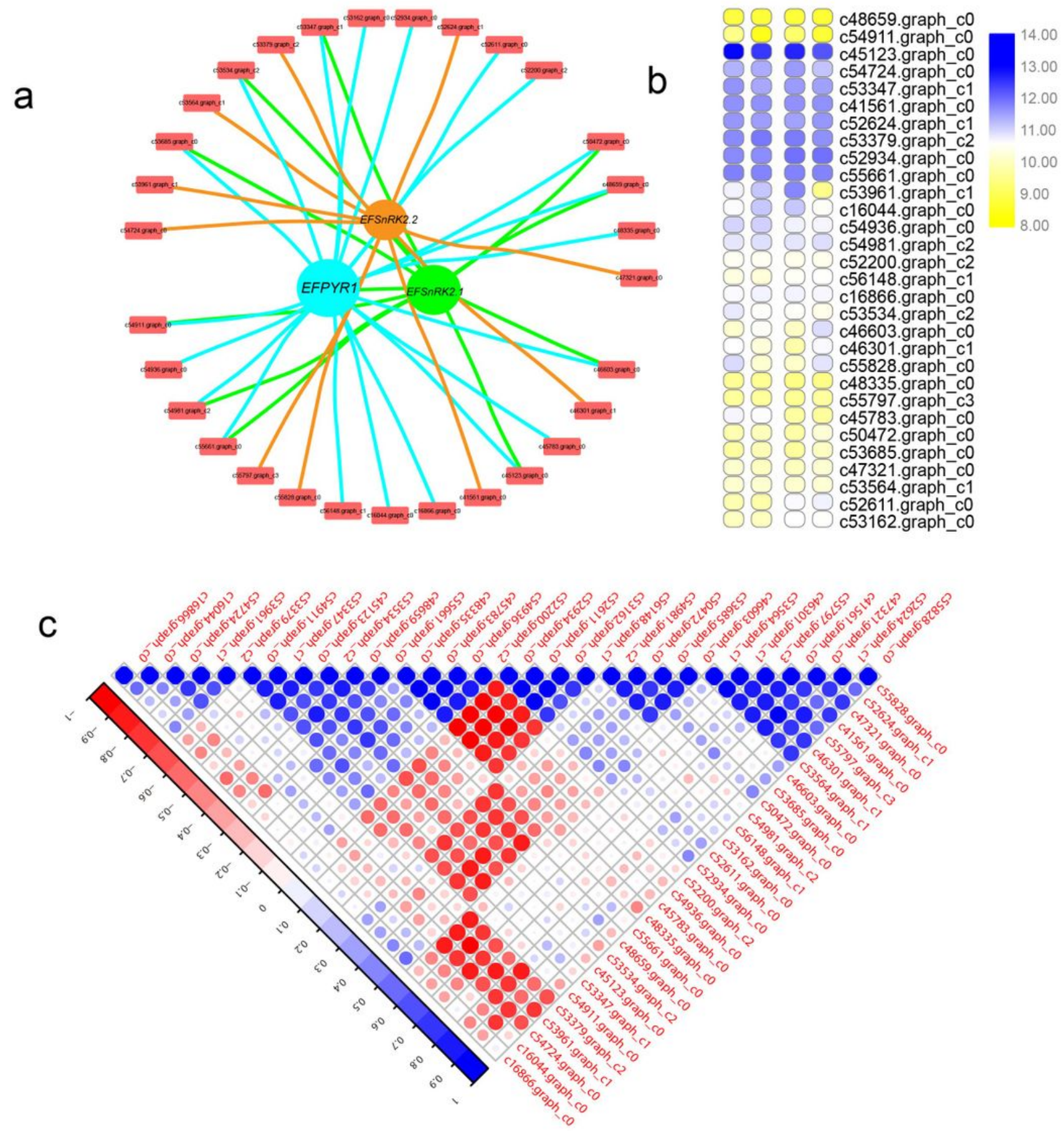

Figure 8

Network hubs regulating genes in different seed developmental stages. (a) Network hubs (EfPYR1, EfSnRK2.1 and EfSnRK2.2) regulating genes in differentiation stage; (b) Expression patterns of regulating genes; (c) Correlations of regulating genes; Each correlation is shown by circle shapes of blue and red. Blue indicates a positive correlation, and red indicates a negative correlation. 


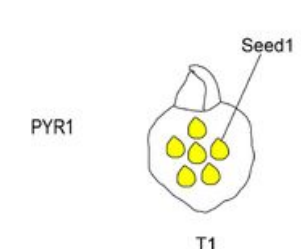

T1

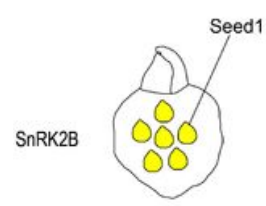

T1

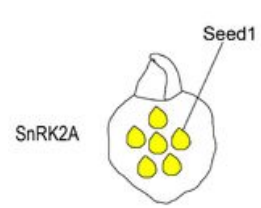

T1

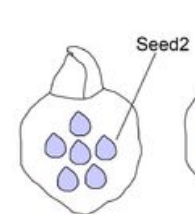

T2

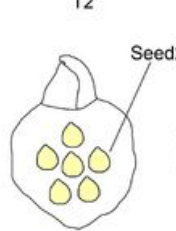

T2

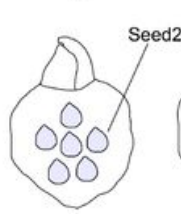

T2

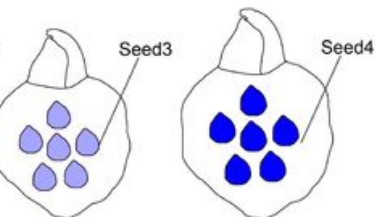

T3
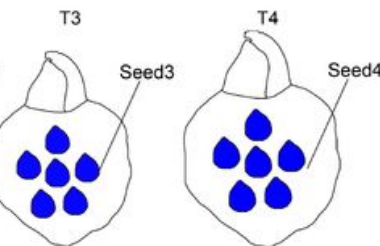

T3

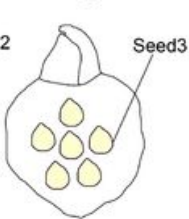

T3

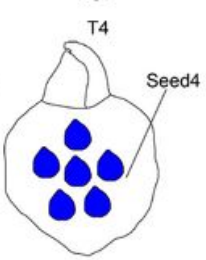

T4
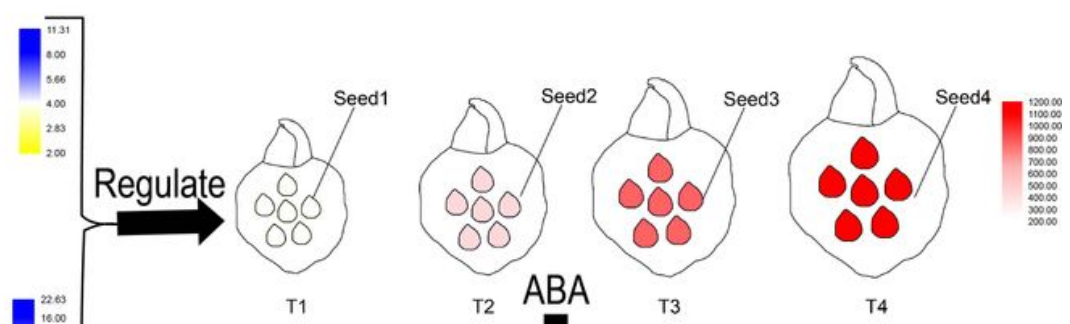

$\mathrm{PCC}=0.974$

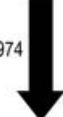

Seed starchness

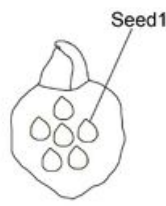

T1

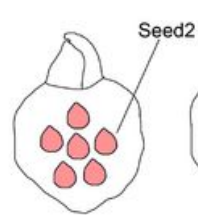

T2

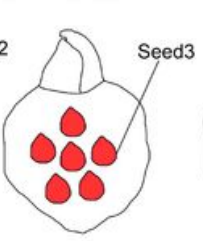

T3

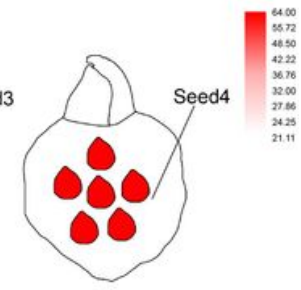

4

Figure 9

Expression patterns of hub genes and the content of $A B A$ in Euryale ferox seeds.

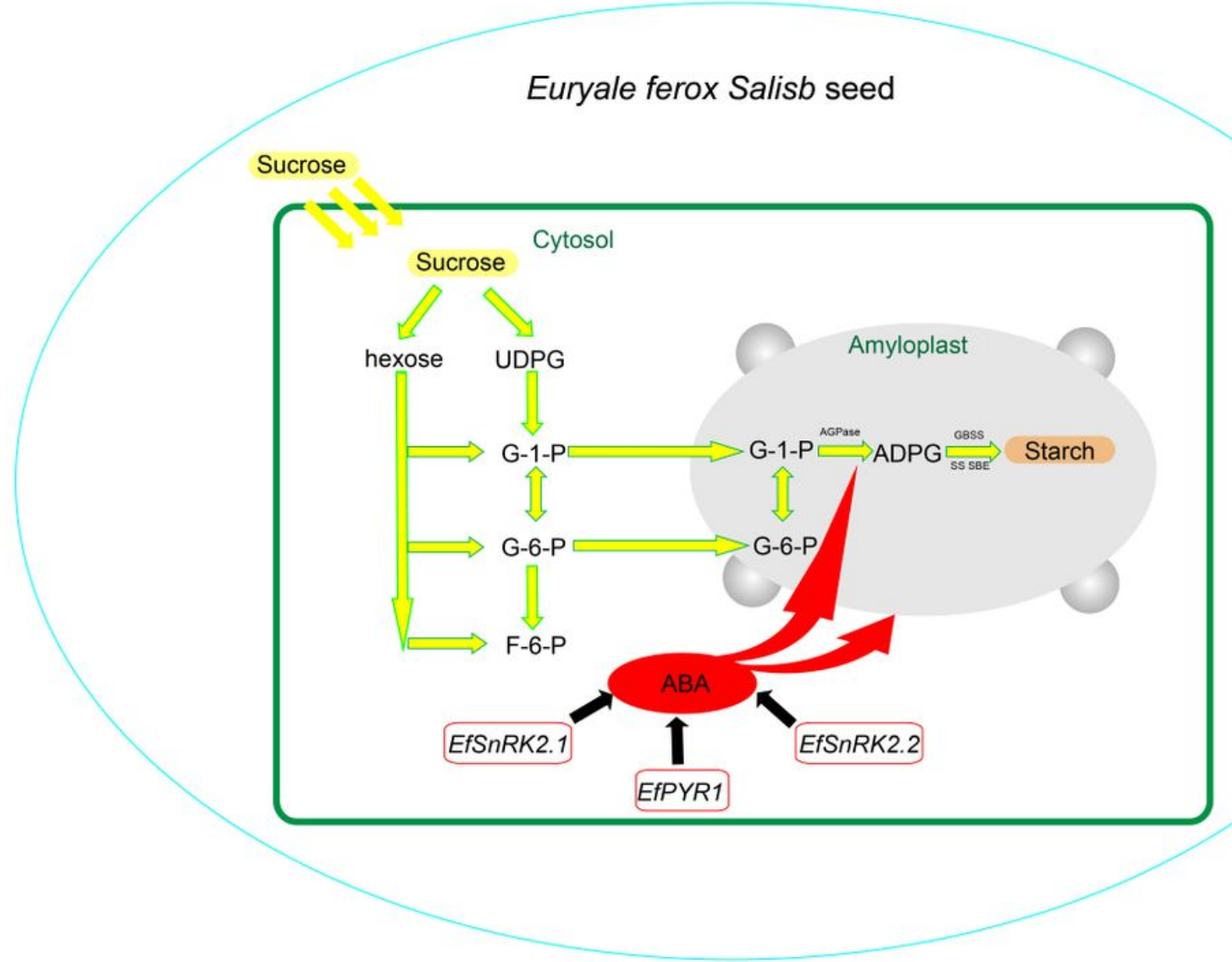

Figure 10 
Schematic diagram showing the putative role of ABA in promoting starch synthesis in Euryale ferox seeds.

\section{Supplementary Files}

This is a list of supplementary files associated with this preprint. Click to download.

- SupplementaryFile2.doc

- FigS.1.png

- FigS.4.jpg

- FigS.2.jpg

- FigS.3.jpg

- SupplementaryFile1.xls 